\title{
Adaptive immunity to vaccinia virus: revisiting an old friend
}

\author{
David C Tscharke \\ The Australian National \\ University, School of \\ Biochemistry \& Molecular \\ Biology, Canberra, ACT, \\ 0200, Australia \\ Tel.: +61261253020; \\ Fax: +61261250313 \\ david.tscharke@anu.edu.au
}

\begin{abstract}
The study of immunity to vaccinia virus has had a renaissance in recent years, largely owing to a desire to produce a safe and efficacious vaccine against smallpox in the context of biodefense concerns. This review focuses on three areas that have seen recent advances: the mapping of epitopes, data from the clinic (including efforts to determine the longevity of responses in humans and recent smallpox vaccine trials) and the use of animal models to determine the requisites for successful immunity and the effect of vaccinia virus immunomodulators on adaptive immune responses. This is intended to be a snapshot of areas generating current interest rather than a comprehensive review, and each area is discussed in terms of current achievements and challenges for the future.
\end{abstract}

Vaccinia virus (VACV) was the live virus vaccine used to eradicate smallpox and deserves to be remembered as a friend of the human race [1]. Given this celebrated history, one might expect that VACV would be one of the best understood of all viruses, but this is not the case. Even the origin of the virus is obscure; its natural host/s is unknown and how and when VACV came to replace cowpox virus as the preferred smallpox vaccine remains a mystery. This is not to say we know nothing about VACV and its immunology. The virus has been studied in animal models for more than half a century and the history of smallpox vaccination is a rich, if somewhat anecdotal, source of information. In addition, the use of recombinant VACVs in animal models and human clinical trials provides further useful data. However, earlier studies have not had the benefit of the tools of modern molecular immunology and studies based on recombinants rarely have an interest in VACV itself at their heart and so are often excluded from the 'VACV fact file'.

Current interest in VACV and its immunology largely stems from biodefense considerations [2]. The odds that variola virus might be deliberately released are not known, but the devastation it would cause if transmission was not promptly checked is clear. Another threat posed by a poxvirus disease is human monkeypox. Outbreaks of this emerging disease appear to be increasing, possibly due to the cessation of smallpox vaccination [3,4]. In past monkeypox outbreaks, human-human transmission was limited, but there is considerable genetic variation between monkeypox isolates and it should not be assumed that the species barrier is impenetrable. An understanding of VACV immunology is required to design and test new vaccines for lethal poxvirus disease. The current smallpox vaccine has an unacceptably high rate of adverse reactions and cannot be used in several populations, including the immunocompromised, those with atopic dermatitis and those with a history of heart disease [5,6]. Poxvirus diseases aside, recombinant (r)VACVs are in clinical trials as vaccines for infectious disease and cancer. In general, the foreign genes in these vaccines are very well characterized, but the vector has received less attention. Two facts about VACV are relevant in this context: first, VACV is a large and immunogenic vector, so these vaccines will inevitably elicit strong anti-VACV responses that should be taken into account, and, second, VACV expresses many genes that modulate immunity and their effects on immune responses merit exploration.

The main purpose of this review is to discuss recent VACV literature in a few key areas. For readers wanting a more comprehensive historical context, I recommend Fenner and colleagues' heroic 'Smallpox and its Eradication', written for the WHO [1,101], and an excellent new comprehensive review summarizing new and older papers with a focus on immunological memory in the context of smallpox vaccination [7]. In addition, while VACV shares a large degree of sequence similarity with its orthopoxvirus cousin's ectromelia (mousepox) and variola (smallpox) viruses, its pathogenesis is very different and its immunology is likely to be equally unique. This review deals exclusively with VACV and readers are cautioned against the extrapolation of these findings to smallpox or other orthopoxviruses.

\section{Specificity of immune responses to VACV $T$ cells}

The area of VACV immunology that has seen the greatest activity in the last 5 years is epitope discovery. Most outstanding has been the identification 
of antigenic determinants for $\mathrm{CD}^{+} \mathrm{T}$ cells. The first report of a VACV CD8 ${ }^{+}$T-cell epitope appeared in 2003 [8], and the present total stands at 16 publications with more than 140 peptide sequences reported (Table 1; also see the Immune Epitope Database and Anlaysis Resource [102] for an up-to-date list). The mapping methods range from relatively small-scale projects where a subset of genes are chosen for predicting likely epitopes, to full virus genome-scale projects. The most prolific of these have come from the groups of Sette and Koelle [9-12]. It is worth noting that publications reporting new epitopes vary widely in the quality of their analysis and, thus far, none have demonstrated conclusively that the peptides found using in vitro assays are indeed the same as the epitope that generates the response in vivo [13]. This would require verification by mass spectroscopy and/or evidence demonstrating that deleting the epitope from VACV eliminates the response measured in vitro. Indeed, some of the reported peptides were used in assays at unphysiologically high concentrations and/or their utility has not been reproduced in other studies. In addition, some

Table 1. Summary of studies mapping vaccinia virus CD8+ T-cell epitopes.

\begin{tabular}{|c|c|c|c|}
\hline MHC & Species* & Number ${ }^{\ddagger}$ & Ref. \\
\hline$H-2 D^{b}$ & Mouse & 21 & {$[11,18,22]$} \\
\hline $\mathrm{H}-2 \mathrm{~K}^{\mathrm{b}}$ & Mouse & 25 & {$[11,18,22,23]$} \\
\hline$H-2 D^{d}$ & Mouse & 1 & {$[19]$} \\
\hline $\mathrm{H}-2 \mathrm{~K}^{\mathrm{d}}$ & Mouse & 1 & [19] \\
\hline$H-2 L^{d}$ & Mouse & 1 & [19] \\
\hline HLA-A1 & Human & 12 & {$[9,12]$} \\
\hline HLA-A2 & Human & 20 & {$[9,12,14,24-26]^{\S}$} \\
\hline HLA-A3 & Human & 13 & [9] \\
\hline HLA-A24 & Human & 5 & {$[9,12]$} \\
\hline HLA-B7 & Human & 7 & {$[9,26]$} \\
\hline HLA-B44 & Human & 14 & {$[9,12]$} \\
\hline HLA-other" & Human & 2 & {$[12,21,27]$} \\
\hline HLA-A2 & Mouse & 16 & {$[8,10,28]$} \\
\hline HLA-A11 & Mouse & 4 & {$[10]$} \\
\hline HLA-B7 & Mouse & 3 & [10] \\
\hline
\end{tabular}

*Species in which original mapping was done. Epitopes for HLA-A2, -A11 and B7 in the last three rows were mapped in HLA transgenic mice.

${ }^{\ddagger}$ Reported epitopes may not all be defined at the level of minimal peptide and analysis/verification is highly variable between, and in some cases within, reports. ${ }^{s}[24]$ defines a peptide that is presented on the surface of vaccinia virus-infected cells. As yet, it is not known if this is recognized by $T$ cells.

"Includes studies where the MHC restriction was not determined.

HLA: Human leukocyte antigen; MHC: Major histocompatibility complex. papers fail to show major histocompatibility complex restriction or map epitopes to minimal peptide sequences. However, taken as a whole, they shed light on the overall shape of $\mathrm{CD}^{+} \mathrm{T}$ cell-responses to VACV.

The breadth of $\mathrm{CD}^{+} \mathrm{T}$-cell responses to VACV is dramatic in both humans and mice and there is no temporal or functional class of VACV protein that is devoid of $\mathrm{CD}^{+} \mathrm{T}$-cell epitopes. This corrects the long-held view that VACV late genes cannot be good targets for $\mathrm{CD}^{+} \mathrm{T}$ cells [14], based on work with a series of recombinant VACVs carried out in the 1980s [15]. What remains to be shown is the rigidity of the lines between temporal classes of genes. A careful look at the data for one 'late' gene found to have a $\mathrm{CD}^{+}{ }^{+} \mathrm{T}$-cell epitope shows partial expression of this gene in the early stages [16]. It will be important to investigate these nuances to provide a full understanding of VACV antigen presentation.

An immunodominance hierarchy exists, but is not as extreme as has been documented for some other viruses, such as the herpes simplex virus [17]. A single epitope is the target for roughly $25-50 \%$ (depending on the route of infection) of all antiVACV CD8 ${ }^{+} \mathrm{T}$ cells in C57BL/6 mice $[11,18]$ and variable responses to different epitopes are observed in BALB/c mice [19] and human volunteers [9,12]. The existence of many strongly immunogenic epitopes in VACV suggests that virus escape from $\mathrm{CD} 8^{+} \mathrm{T}$ cells is highly unlikely.

A handful of VACV proteins are sources of several CD8 ${ }^{+}$T-cell epitopes, the most outstanding examples being D1 (mRNA capping enzyme), D5 (ATPase) and B8 (soluble receptor for interferon [IFN]- $\gamma$ ) with six, five and five epitopes, respectively. Whether this means these proteins have greater inherent immunogenicity for $\mathrm{CD}^{+} \mathrm{T}$ cells remains to be seen, but is an area worthy of attention.

Comparing the results from work using human leukocyte antigen (HLA) transgenic mice and vaccinated human volunteers reveals a surprising lack of overlap in the epitopes found [20], and, for this reason, these studies are separated in Table 1. This suggests that for poxviruses, and perhaps complex immunogens in general, HLA transgenic mice may not be as useful a tool for finding human $\mathrm{CD}^{+}$T-cell epitopes as they have been for smaller viruses.

While many epitopes have been mapped, relatively few vaccinated individuals have been investigated. Of 20 HLA-A2 restricted epitopes found thus far, some have been found in only a 
single donor. As the mapping continues and more peptides are added to the list, it will become impractical to measure responses to each peptide in large cohorts. For such future studies it is not clear whether it will be best to find and focus on peptides that are immunogenic in the greatest number of donors or simply use pools of peptides to detect all possible responses. Some clarity may emerge after screening many individuals with a large number of peptides, not an insubstantial task.

The route of immunization and the strain of VACV used were found to have unexpected effects on the immunogenicity of $\mathrm{CD} 8{ }^{+} \mathrm{T}$-cell epitopes in a mouse model, suggesting that comparing responses to different strains of VACV vaccines and various routes using individual peptides (or MHC-peptide tetramers) may be complicated [18].

We are at the beginning of a new era of research into VACV-specific $\mathrm{T}$ cells. While the mapping of $\mathrm{CD}^{+} \mathrm{T}$-cell epitopes for such a large virus may have been difficult, two challenges remain. First, to carry the momentum gained through the mapping experience into experiments that give insight into the immunology of VACV. Second, to map the specificity of $\mathrm{CD}^{+}{ }^{+}$T-cell responses. A single paper has reported several $\mathrm{CD}^{+}{ }^{+} \mathrm{T}$-cell epitopes in humans, but the MHC restriction was not determined and minimal determinants were not identified [21]; other $\mathrm{CD}^{+} \mathrm{T}$-cell epitope mapping projects are underway and the results are eagerly awaited.

\section{Antibodies}

Many targets for anti-VACV antibodies have been known for some time as a result of steady progress over many years. A new study using a VACV proteome-wide approach has added to our list of targets and helped rank the full list in order of immunogenicity [29]. In addition, proteome array technology has allowed for the easy comparison of sera from humans, mice and monkeys, demonstrating that the majority of detected antibody targets are conserved across these three species. The actual conservation may be even higher as this study used different VACV strains (or vaccines) and the monkey had recently (10 days) been challenged with monkeypox. A second recent study used a random genomic library to generate a list of antibody targets for VACV [27].

Antibodies that neutralize VACV or inhibit its spread are of prime interest, but it can be difficult to distinguish these two mechanisms. This requires appropriate assays and the fine mapping of epitopes. VACV has a complex morphogenic pathway with several infectious forms. The most relevant of these are the intracellular mature virus (IMV) and extracellular enveloped virus (EEV), with these two forms considered to be of importance in the spread between and within hosts, respectively [30,31]. An EEV is essentially an IMV wrapped with an extra membrane that includes several novel viral proteins and shields the IMV set of antibody targets. The function of EEV in the extracellular spread of the virus can be seen in vitro as 'comet' formation in plaque assays, and this assay has been used as a surrogate for more direct EEV neutralization assays by some workers. However, fine mapping of epitopes that can inactivate EEV by binding to the B5 protein (an EEV membrane protein) revealed that direct EEV neutralization was not always the cause of comet inhibition [32]. These studies, and others like them, are needed to dissect the mechanisms of antibody-mediated protection. Additionally, the incorporation of neutralization assays for both forms of virus in further humans trials will also be necessary [33].

\section{Human studies Longevity of immune responses}

The kinetics, and especially the duration, of adaptive immune responses to VACV have received attention in an effort to assess the level of immunity to smallpox remaining in the community (Table 2). Levels of anti-VACV B cells, antibodies and neutralizing antibodies drop from their post-vaccination peak until a time period of approximately a year, and thereafter remain stable [34-37]. The only exception appears to be antibodies that are able to neutralize the EEV form of VACV [36]. VACV-specific $T$ cells are also long lived, but their numbers decline over time, with at least two studies measuring half lives in the order of $8-15$ years. One notable finding is that while in most individuals this gradual decline is observed for $\mathrm{CD}^{+} \mathrm{T}$ cells, around half of vaccinees lose detectable $\mathrm{CD} 8^{+} \mathrm{T}$-cell responses to VACV, indicating that the maintenance of these two populations of $\mathrm{T}$ cells is independent.

\section{Recent clinical trials}

New human trials of smallpox vaccines are now generating substantial amounts of information (see Table 3 for a summary) and two themes are emerging.

Dose studies with current vaccines [40-45] have demonstrated that antibody titers correlate with lesion size and not necessarily with dose. It is 
Table 2. Persistence of adaptive immune responses to vaccinia virus.

\begin{tabular}{|c|c|c|c|c|c|}
\hline Study & Antibody (total) & Antibody (neut.) & $\mathrm{CD}^{+} \mathrm{T}$ cells & $\mathrm{CD}^{+} \mathrm{T}$ cells & Ref. \\
\hline Hammerlund (2003) & Stable & & $T_{1 / 2}$ up to 10.6 years & $T_{1 / 2}$ up to 15.5 years ${ }^{*}$ & [34] \\
\hline Crotty (2003) & Stable ${ }^{\ddagger}$ & Stable & All T cells $T_{1 / 2}=14$ years & & [35] \\
\hline Amara (2004) & & & Long lived & Long lived $^{*}$ & [38] \\
\hline Combadiere (2004) & & & Long lived & Long lived $^{*}$ & [39] \\
\hline Viner (2005) & & Stable $(\mathrm{IMV})^{\S}$ & & & [36] \\
\hline Putz (2005) & Stable & & & & [37] \\
\hline
\end{tabular}

${ }^{*} C D 8^{+} T$ cells become undetectable in around half of vaccinees, while CD4+ $T$ cells are more reliably maintained.

${ }^{\ddagger}$ Anti-VACV memory $B$ cell numbers were also found to be stable.

$\S$ Neutralizing antibody to the IMV form of VACV was stable but EEV-neutralizing activity waned over time.

EEV: Extracellular mature virus; IMV: Intracellular mature virus; neut: Neutralizing; $T_{1 / 2}$ : Half-life; VACV: Vaccinia virus.

worth noting that actual dose is likely to be variable after scarification and that lesion size may correlate better with actual, rather than intended dose. However, a study that included inoculation by intradermal and intramuscular injections (methods that would be expected to give a more accurate dosing) also noted that the highest antibody titers were found in vaccines that developed pox lesions [46]. Thus, there appears to be a link between reactogenicity (e.g., mild adverse events) and immunogenicity with replicating vaccines, and this represents a challenge to the development of a kinder smallpox vaccine. This finding suggests that nonreplicating vaccines, such as modifed vaccinia virus ankara (MVA), that do not cause lesions will be less effective or must induce immunity via substantially different pathways. Perhaps this is reflected in the significantly higher doses of MVA (1-3 orders of magnitude) typically required to achieve levels of antibodies and $T$ cells similar to those induced by replicating strains in animal and clinical trials [47-49].

Revaccination of previously vaccinated individuals leads to rapid rises in humoral- and cellmediated immunity to levels higher than those achieved in individuals vaccinated for the first time [35,50]. This supports other studies demonstrating that immunity to VACV is long lived (see above). However, other longer-term studies have found no correlation between the number of times a person is vaccinated and the magnitude of antibody or T-cell responses [34,36,38,39]. Together, these studies suggest that, while boosting occurs, it is of short duration and does not lead to a stable increase in anti-VACV immunity.

Few studies have been published that ask deeper questions about adaptive immune responses to VACV in humans. A recent study quantified neutralizing antibody responses to IMV and EEV forms of virus after vaccination with VACV strain Lister and examined the targets of these antibodies [33]. A major finding was that, while IMV neutralization was mediated by antibodies to multiple VACV proteins, EEV-neutralizing antibodies targeted the B5 protein exclusively. Moving beyond antibodies, two papers by Crowe's group have begun to characterize the quality of $\mathrm{CD}^{+} \mathrm{T}$-cell responses to VACV in humans. The first study examined the expression of perforin and granzyme (the molecular effectors of cytotoxicity) in $\mathrm{CD}^{+} \mathrm{T}$ cell [51], and the second provided a broad look at systemic cytokine responses induced by VACV vaccination and their association with adverse events [52]. While there is growing opinion that protection in most models of lethal poxvirus infection is mediated by neutralizing antibodies alone, all models have their flaws and it appears prudent that we aim to match as many aspects of VACV immunity between the old smallpox vaccine and any new candidate. As noted above, this is perhaps most pertinent for nonreplicating strains such as MVA. Unfortunately, while trials with replicating vaccines such as ACAM2000 have tended to include comparisons with current smallpox vaccines (e.g., Dryvax ${ }^{\circledR}$, Wyeth Laboratories, USA) and are usually given by the same route [53-55], nonreplicating vaccines such as MVA are given by different routes and often without comparison groups receiving a replicating vaccine [49]. In the absence of these comparison groups in clinical trials, follow-up studies to compare the quality and quantity of responses between replicating and nonreplicating vaccines are not possible.

Despite the higher profile of smallpox vaccine trials, the majority of human clinical trials using VACV are for recombinant vaccines, with more than 15 related papers being published in the last year. Almost all of these focus exclusively on 
Table 3. Smallpox vaccines and vaccinia virus strains, ancestry and clinical trials.

\begin{tabular}{|c|c|c|c|}
\hline Name & Company & Ancestry & Clinical references \\
\hline Dryvax ${ }^{\circledR}$ & Wyeth Laboratories & $\mathrm{NYCBH}$ & {$[40,44,45,50,56,57]$} \\
\hline CCSV & DynPort Laboratories & Connaught/NYCBH & {$[55,58,59]$} \\
\hline ACAM2000 & Acambis & Dryvax/NYCBH & {$[53,54]$} \\
\hline APSV & Aventis Pasteur & NYCBH & {$[41,43,52]$} \\
\hline Western Reserve & Nil, (virulent lab strain) & NYCBH & \\
\hline Lister/Elstree & Swiss Serum Institute & Lister/Elstree & [33] \\
\hline Lister & Taiwan CDC & Lister/Elstree & [42] \\
\hline LC16m8 & VaxGen & Lister/Elstree & \\
\hline Lancy-Vaxina & Berna Biotech & Lister/Elstree & {$[60,61]$} \\
\hline IMVAMUNE (MVA) & Bavarian Nordic & MVA & [49] \\
\hline
\end{tabular}

MVA: Modified vaccinia virus ankara; NYCBH: New York City Board of Health; VACV: Vaccinia virus.

measuring responses to the foreign antigen and, as such, provide some information on the timing of responses to VACV (assuming that responses to most epitopes follow similar kinetics), but not on the magnitude. In addition, frequently only a single aspect is measured, for example $\mathrm{CD}^{+}$ $\mathrm{T}$ - cell responses. Of these, one report stands out as providing useful information about rVACV vaccines in general and demonstrates that responses to the vector dominate in humans [62], echoing previous findings in a mouse model [63].

\section{Mouse models \\ Requisites for overall immune control of VACV}

Attempts to determine which effectors of the adaptive immune response are key for the overall control of primary VACV infection have been made for as long as these responses have been studied. New work in mouse models has revisited this issue, but with variable conclusions. One report in which intraperitoneal infection of C57BL/6 was used suggests that mice lacking either $\mathrm{CD}^{+} \mathrm{T}$ cells or $\mathrm{B}$ cells fail to produce an immunoglobulin $\mathrm{G}$ response to $\mathrm{VACV}$, and this lack of a mature antibody response compromises virus control [64]. This supports previous work with a cutaneous model in the same mouse strain, suggesting a limited role for $\mathrm{CD} 8^{+} \mathrm{T}$ cells. In contrast, a study using intranasal VACV infection of $\mathrm{BALB} / \mathrm{c}$ mice found $\mathrm{CD} 8^{+} \mathrm{T}$ cells to be more important than $\mathrm{CD}^{+} \mathrm{T}$ cells in protecting from primary disease [47]. Another group examining the role of T-bet, a transcription factor required for the dominance of T-helper type 1 responses, found that even if antibody responses were normal, other deficiencies in T-bet knockout mice led to increased disease [65]. The T-bet knockout was on the BALB/c back- ground and the intraperitoneal route was used. T-bet deficiency has multiple effects, so these are not simple experiments to interpret but they do suggest that cellular functions have value beyond supporting adequate antibody responses in this model. Together, this somewhat contradictory set of findings highlights the need for a better understanding of the particular models used and susceptibility of different mouse strains. Indeed, various VACV immunomodulators have been found to have very different roles, and inflammatory infiltrates differ when different models of infection are used $[66,67]$. It is also worth noting that while one effector may appear dispensable for survival in a particular model, this does not imply that it plays no role in an immunocompetent host and that perhaps a focus on the whole system is more appropriate. In terms of important molecules, since the mid-1990s, there has been broad agreement that IFN- $\gamma$ is critical and the T-bet paper previously cited is a recent example of work that supports this contention.

Protection against a lethal VACV challenge after immunization (or a previous VACV infection) has also been examined recently. Comparing such studies is even more difficult than studies of primary infection because the nature (and type) of immunization as well as the dose, strain and particular challenge model used may all affect the outcome. Perhaps not surprisingly, either anti-VACV antibodies, CD8 ${ }^{+} \mathrm{T}$ cells or both can be found to be protective depending on the study; findings in individual studies most often reflect the nature of the immunization (e.g., immunizations that induce a robust anti-VACV antibody response mediate protection via antibodies), but the stringency of the challenge model may also be an important factor $[23,28,47,68-70]$. 
There are few specific models of clinical problems associated with VACV; one good recent example being the integration of mouse and human culture models to investigate eczema vaccinatum (Box 1) [71,72].

\section{VACV immune modulators \& adaptive immune responses}

VACV expresses an impressive array of proteins that modify the host response to infection and these have been the focus of many efforts to understand the basis of VACV virulence. It has been assumed that the expression of many of these genes will adversely affect adaptive immune responses to VACV, but this hypothesis has not been well tested. The first description of a VACV deletion mutant that induced better immunity than a control was over 15 years ago [73]. This paper suggested that inactivation of each of the two VACV serpins (B13 and A24) via the introduction of a foreign gene into these regions improved antibody responses to the recombinant protein. However, the control virus (but not serpin deletions) was thymidine kinase- negative, and work with an independent B13R deletion virus from the same laboratory failed to replicate the finding when total antiVACV antibody was measured [67]. Two recent publications implicate another two VACV immuno-modulators in the suppression of optimal immune responses. In the first, Staib and colleagues examined the VACV-soluble interleukin (IL)-1 $\beta$ receptor in the nonreplicating MVA strain of VACV [74], and in the second, Clark and colleagues investigated A41, a protein

\section{Box 1. Interleukin-4, antimicrobial peptides \&}

\section{eczema vaccinatum.}

- Eczema vaccinatum is a complication of smallpox vaccination occurring in vaccinees with atopic dermatitis and characterized by uncontrolled vaccinia virus (VACV) infection in the skin. Overexpression of interleukin (IL)-4 and underexpression of antimicrobial peptides are observed in atopic skin and key findings by Leung and colleagues neatly link these two features with poor control of VACV $[71,72]$.

- LL-37, an antimicrobial peptide that is deficient in atopic skin, has potent anti-VACV activity.

- Mice deficient in the murine counterpart of LL-37 (CRAMP) demonstrated more frequent lesion formation after scarification with VACV.

- Adding IL-4 and -13 to keratinocyte cultures reduced the production of LL-37 after VACV infection.

- Treating skin biopsies from patients with atopic dermatitis with anti-IL-4 and IL-13 antibodies increased LL-37 production and reduced VACV gene expression after infection. similar to chemokine-binding proteins but with no known target, in a replicating VACV (strain WR) and in MVA [75]. Both papers focused on $\mathrm{CD}^{+} \mathrm{T}$-cell responses, demonstrating that these were increased in mice vaccinated with VACV's lacking the gene of interest compared with parental and revertant viruses. In addition, VACV challenge models were used to show that the deletion of an immunomodulator improved vaccine efficacy, but neither group examined $\mathrm{CD}^{+} \mathrm{T}$ cells or humoral responses. In contrast to these two papers, a third, which examined a number of deletion mutants each lacking several genes, found no evidence of improved immune responses [76]. This study measured antibody to VACV and a foreign antigen expressed by all viruses and $\mathrm{CD}^{+} \mathrm{T}$ cells to an epitope in the foreign antigen. Two of the viruses examined in this report lack the soluble IL-1 receptor and therefore the findings contradict those of Staib and colleagues described above. However, the two papers use different strains of virus, one a replication competent strain and the other an MVA, and examine immunogenicity to different targets. In addition, experiments using viruses with multiple gene deletions will always be difficult to interpret. It might appear reasonable to assume that all immunomodulators will dampen immunity and so the more genes that are deleted, the more likely it is that a significant effect will be detected. This view is contradicted by evidence that some immunomodulators can increase immune functions, such as inflammation [77], and for this reason the term 'immune modulation' is preferable to 'immune evasion'. Virus-host interactions are complex and not all the functions of the immune system will necessarily be deleterious for viral growth and propagation to the next host. Finally, the functions of VACV immunomodulators in animal models (or vaccinated humans) may not resemble those in its elusive natural host, in which these genes have presumably evolved.

\section{Conclusion}

The two most significant achievements in VACV immunology in the last 5 years have been the mapping of $\mathrm{CD} 8{ }^{+} \mathrm{T}$-cell-epitopes and a better appreciation of the long term persistence of humoral and cellular immunity to the virus. The sheer breadth of the cellular response poses questions as to how we combine our epitope knowledge with samples that are now being provided by clinical trials of alternative smallpox vaccines. With a few notable exceptions, data from animal models are not having a great impact on human 
Executive summary

\section{Specificity of $T$-cell responses}

- CD8 + T-cell responses to vaccinia virus (VACV) are very broad and targets include representatives from all temporal and functional classes of genes.

- There is surprisingly little overlap between the sets of epitopes mapped using human donors and human leukocyte antigen transgenic mice.

- The large number of epitopes mapped using human donors contrasts with the relatively few individuals investigated to date. The number of mapped epitopes that will be immunogenic in a sizeable proportion of vaccinated individuals is not known.

- Adequately characterized CD4+ T-cell epitopes for VACV have yet to be published.

\section{Specificity of $B$-cell responses}

- A VACV proteome-wide approach has added to our list of antibody targets, ranked targets in order of immunogenicity and allowed comparisons of the specificity of human, monkey and mouse sera.

- Mapping of antibody epitopes is requiered to distinguish the various roles of anti-VACV antibodies.

\section{Longevity of anti-VACV responses in humans}

- Levels of anti-VACV B cells, total antibody and neutralizing antibody (with the possible exception of extracellular enveloped virus-neutralizing antibody) all remain stable for the life of a vaccine after initial declines in the first year.

- Anti-VACV T cells also persist for decades but gradually decline with a half-life in the order of a decade. VACV-specific CD4+ $T$ cells frequently persist at measurable levels after CD8 ${ }^{+} T$ cells recognizing the virus fall below the limit of detection.

\section{Lessons from recent clinical trials}

- The magnitude of immune responses correlates with the severity of 'take' and minor adverse events, but not necessarily dose; immunogenicity appears to be inextricably linked to reactogenicity.

- Induction of immune responses is more rapid and levels are higher in previously vaccinated individuals in the months after vaccination, but this boosting is short lived and does not lead to higher levels of immunity over the long term.

- The application of epitope information for $C D 8^{+} T$ cells has yet to find its way into the analysis of samples from clinical trials and there remain very few examples of studies examining qualitative aspects of immune responses.

\section{Lessons \& challenges from mouse models}

- There are mixed results from mouse models in terms of the requisites for effective immune defense against primary VACV infection and this is likely to be a reflection of the individual models used.

- $C D 8+$ T-cell responses are usually reported to be paramount in BALB/C mice, where the intranasal route is in common use, but not in C57BL/6 mice where intraperitoneal or dermal routes predominate.

- The integration of mouse models and human culture models has proved highly successful in defining a role for antimicrobial peptides in the local control of VACV in the skin.

\section{Immunomodulators \& adaptive immunity to VACV}

- Evidence is emerging that the removal of some immunomodulators may improve the generation of adaptive immune responses to VACV and its performance as a vaccine.

- A better understanding of the role of immunomodulators is required for the rational improvement of VACV as a vaccine.

vaccine design, in part due to the conflicting data from different models. These models need refinement and the reasons for differences need to be exposed. A better understanding of VACV immunomodulators, in part acquired by the use of animal models, is required in order to facilitate attempts to engineer better VACV vaccines. Finally, although not discussed here, work with innate immunity and particularly the interface between innate and adaptive immunity are required to develop a complete understanding of immunity to VACV.

\section{Future perspective}

Biodefense considerations have created more interest in VACV in recent years and most of the advances noted here would not have occurred without this impetus. Assuming the political will remains, it is likely that this progress will lead to a satisfactory replacement vaccine for smallpox being identified, manufactured and stockpiled within the coming years. If this occurs, and in the absence of an outbreak of a lethal human poxvirus disease, interest in VACV is likely to wane once more, so now is a good time to ask what larger legacy can be left by working with VACV?

Smallpox was the first acute disease to be eliminated, but in the developed world our only form of exposure to many other pathogens is as a vaccine. In the complete absence of potential boosting by casual exposure to pathogens, such as poliovirus and others, the question of long-term immunity is of increasing importance, lest some of these diseases re-emerge. The current ability to carry out 
longitudinal studies in human populations after VACV vaccination presents us with a rare opportunity to study the persistence of immunity in the absence of antigen. Unexpected findings, such as the curious loss of VACV-specific $\mathrm{CD}^{+} \mathrm{T}$ cells in many individuals, beg further explanation and are likely to have implications for other diseases.

In a similar vein, the extensive list of $\mathrm{CD}^{+}$ T-cell epitopes now makes VACV the best model for understanding the finer details of immunodominance and the potentially different roles of $\mathrm{CD}^{+} \mathrm{T}$ cells of differing specificity. It will also reduce the need to use rVACV-expressing model antigens for these studies, as is the current state of the art [78]. Ideally, the field will converge on one, or a few well-characterized models, enabling better comparisons between studies. If this occurs and tools such as T-cell receptor-transgenic mice become available, the VACV model for viral immunity will gain better general acceptance as one that can produce data of broad relevance.

Finally, work originating in mouse models will produce the information needed to understand the roles of VACV immunomodulators in vivo. In turn, this will prompt further attempts to improve VACV as a vaccine by optimizing the catalogue of immunomodulators expressed. In the absence of widespread vaccination against smallpox, recombinant vaccines based on these new vectors will make their path into clinical trials and, if successful, beyond.

\section{Acknowledgements}

DCT is supported by an Australian NHMRC RD Wright Career Development Award \#418108.

\section{Bibliography}

Papers of special note have been highlighted as either of interest $(\bullet)$ or of considerable interest $(\bullet \bullet)$ to readers.

1. Fenner F, Henderson D, Arita I, Jezek Z, Ladnyi I: Smallpox and its Eradication. World Health Organization, Geneva, Switzerland (1988).

2. Lane HC, Montagne JL, Fauci AS: Bioterrorism: a clear and present danger. Nat. Med. 7(12), 1271-1273 (2001)

3. Centers for Disease Control and Prevention: Human monkeypox - Kasai Oriental, Democratic Republic of Congo, February 1996-October 1997. MMWR Morb. Mortal Wkly Rep. 46(49), 1168-1171 (1997).

4. Hutin YJ, Williams RJ, Malfait P et al: Outbreak of human monkeypox, Democratic Republic of Congo, 1996 to 1997. Emerg. Infect. Dis. 7(3), 434-438 (2001).

5. Centers for Disease Control and Prevention: Vaccinia (smallpox) vaccine: recommendations of the Advisory Committee on Immunization Practices (ACIP), 2001. MMWR Recomm. Rep. 50, 1-25 (2001).

6. Centers for Disease Control and Prevention: Supplemental recommendations on adverse events following smallpox vaccine in the pre-event vaccination program: recommendations of the Advisory Committee on Immunization Practices. MMWR Morb. Mortal Wkly Rep. 52(13), 282-284 (2003).

7. Amanna IJ, Slifka MK, Crotty S: Immunity and immunological memory following smallpox vaccination. Immunol. Rev. 211, 320-337 (2006).
8. Drexler I, Staib C, Kastenmuller W et al: Identification of vaccinia virus epitopespecific HLA-A*0201- restricted T cells and comparative analysis of smallpox vaccines. Proc. Natl Acad. Sci. USA 100(1), 217-222 (2003).

- $\quad$ First report of a $\mathrm{CD8}^{+} \mathrm{T}$-cell epitope for vaccinia virus (VACV) in any species.

9. Oseroff C, Kos F, Bui HH et al.: HLA class

I-restricted responses to vaccinia recognize a broad array of proteins mainly involved in virulence and viral gene regulation. Proc. Natl Acad. Sci. USA 102(39), 13980-13985 (2005).

-• $\quad$ First large scale CD8 ${ }^{+}$T-cell epitope mapping effort in humans.

10. Pasquetto V, Bui $\mathrm{HH}$, Giannino $\mathrm{R}$ et al: HLA-A*0201, HLA-A*1101, and HLA$\mathrm{B}^{*} 0702$ transgenic mice recognize numerous poxvirus determinants from a wide variety of viral gene products. J. Immunol. 175(8), 5504-5515 (2005).

11. Moutaftsi M, Peters B, Pasquetto V et al.: A consensus epitope prediction approach identifies the breadth of murine $\mathrm{T}\left(\mathrm{CD}^{+}\right)$-cell responses to vaccinia virus. Nat. Biotechnol. 24(7), 817-819 (2006).

-. Uses robust prediction methods to find the majority of VACV CD8 ${ }^{+}$T-cell epitopes in C57BL/6 mice.

12. Jing L, Chong TM, McClurkan CL, Huang J, Story BT, Koelle DM: Diversity in the acute CD8 T-cell response to vaccinia virus in humans. J. Immunol. 175(11), 7550-7559 (2005).

13. Yewdell JW: The seven dirty little secrets of major histocompatibility complex class I antigen processing. Immunol. Rev. 207, 8-18 (2005)
14. Terajima M, Cruz J, Raines G et al.: Quantitation of $\mathrm{CD}^{+} \mathrm{T}$-cell responses to newly identified HLA-A*0201-restricted $T$-cell epitopes conserved among vaccinia and variola (smallpox) viruses. J. Exp. Med. 197(7), 927-932 (2003).

15. Coupar BE, Andrew ME, Both GW, Boyle DB: Temporal regulation of influenza hemagglutinin expression in vaccinia virus recombinants and effects on the immune response. Eur. J. Immunol. 16(12), 1479-1487 (1986).

16. Blasco R, Cole NB, Moss B: Sequence analysis, expression, and deletion of a vaccinia virus gene encoding a homolog of profilin, a eukaryotic actin-binding protein. J. Virol. 65(9), 4598-4608 (1991).

17. Wallace ME, Keating R, Heath WR, Carbone FR: The cytotoxic T-cell response to herpes simplex virus type 1 infection of C57BL/6 mice is almost entirely directed against a single immunodominant determinant. J. Virol. 73(9), 7619-7626 (1999).

18. Tscharke DC, Karupiah G, Zhou J et al.: Identification of poxvirus $\mathrm{CD}^{+} \mathrm{T}$ cell determinants to enable rational design and characterization of smallpox vaccines. J. Exp. Med. 201(1), 95-104 (2005).

- The route of immunization and the strain of VACV have unexpected effects on the immunogenicity of $\mathrm{CD}^{+} \mathrm{T}$-cell epitopes.

19. Tscharke DC, Woo WP, Sakala IG et al.: Poxvirus CD8 ${ }^{+} \mathrm{T}$-cell determinants and cross-reactivity in BALB/c mice. J. Virol. 80(13), 6318-6323 (2006).

20. Terajima M, Ennis FA: Using HLA-transgenic mice to identify immunodominant human $\mathrm{CD}^{+}{ }^{+}$T-cell epitopes - does (genome) size matter? Immunol. Lett. 105(1), 97-98 (2006). 
21. Tang J, Murtadha M, Schnell M, Eisenlohr LC, Hooper J, Flomenberg P: Human T-cell responses to vaccinia virus envelope proteins. J. Virol. 80(20), 10010-10020 (2006).

22. Mathew A, Terajima M, West $\mathrm{K}$ et al.: Identification of murine poxvirus-specific CD8 ${ }^{+}$CTL epitopes with distinct functional profiles. J. Immunol. 174(4), 2212-2219 (2005).

23. Cornberg M, Sheridan BS, Saccoccio FM, Brehm MA, Selin LK: Protection against vaccinia virus $(\mathrm{VV})$ challenge by $\mathrm{CD} 8$ memory $\mathrm{T}$ cells resolved by molecular mimicry. J. Virol. 81(2), 934-944 (2006).

24. Johnson KL, Ovsyannikova IG, Madden BJ, Poland GA, Muddiman DC: Accurate mass precursor ion data and tandem mass spectrometry identify a class I human leukocyte antigen $A^{*} 0201$-presented peptide originating from vaccinia virus. J. Am. Soc. Mass Spectrom. 16(11), 1812-1817 (2005).

25. Dong Y, Denny TN: HLA-A2-restricted human $\mathrm{CD} 8^{+}$cytotoxic $\mathrm{T}$ lymphocyte responses to a novel epitope in vaccinia virus that is conserved among orthopox viruses. J. Infect. Dis. 194(2), 168-175 (2006).

26. Terajima M, Cruz J, Leporati AM, Demkowicz WE Jr, Kennedy JS, Ennis FA: Identification of vaccinia $\mathrm{CD} 8^{+} \mathrm{T}$-cell epitopes conserved among vaccinia and variola viruses restricted by common $\mathrm{MHC}$ class I molecules, HLA-A2 or HLA-B7. Hum. Immunol. 67(7), 512-520 (2006).

27. Sahin U, Türeci Ö, Graf C et al:: Rapid molecular dissection of viral and bacterial immunomes. Eur. J. Immunol. 36(4), 1049-1057 (2006).

28. Snyder JT, Belyakov IM, Dzutsev A, Lemonnier F, Berzofsky JA: Protection against lethal vaccinia virus challenge in HLA-A2 transgenic mice by immunization with a single $\mathrm{CD} 8{ }^{+}$T-cell peptide epitope of vaccinia and variola viruses. J. Virol. 78(13), 7052-7060 (2004).

29. Davies DH, Liang X, Hernandez JE et al.: Profiling the humoral immune response to infection by using proteome microarrays: High-throughput vaccine and diagnostic antigen discovery. PNAS 102(3), 547-552 (2005).

-. Proteome-wide investigation of VACV antibody targets. Ranks VACV proteins by immunogenicity and compares sera from humans, monkeys and mice.

30. Payne LG: Significance of extracellular enveloped virus in the in vitro and in vivo dissemination of vaccinia. J. Gen. Virol. 50(1), 89-100 (1980).
31. Smith GL, Vanderplasschen A, Law M: The formation and function of extracellular enveloped vaccinia virus. J. Gen. Virol. 83(Pt 12), 2915-2931 (2002).

32. Aldaz-Carroll L, Whitbeck JC, Ponce de Leon M et al:: Epitope-mapping studies define two major neutralization sites on the vaccinia virus extracellular enveloped virus glycoprotein B5R. J. Virol. 79(10), 6260-6271 (2005).

33. Putz MM, Midgley CM, Law M, Smith GL: Quantification of antibody responses against multiple antigens of the two infectious forms of vaccinia virus provides a benchmark for smallpox vaccination. Nat. Med. 12(11), 1310-1315 (2006).

- Clinical study that examines neutralizing antibody to both intracellular mature virus and extracellular enveloped virus forms of VACV.

34. Hammarlund E, Lewis MW, Hansen SG et al: : Duration of antiviral immunity after smallpox vaccination. Nat. Med. 9(9), 1131-1137 (2003).

-• Most comprehensive study of the longevity of human adaptive immune responses to VACV.

35. Crotty S, Felgner P, Davies H, Glidewell J, Villarreal L, Ahmed R: Cutting Edge: long-term B cell memory in humans after smallpox vaccination. J. Immunol. 171(10), 4969-4973 (2003).

36. Viner KM, Isaacs $\mathrm{SN}$ : Activity of vaccinia virus-neutralizing antibody in the sera of smallpox vaccines. Microbes Infect. 7(4), 579-583 (2005).

37. Putz MM, Alberini I, Midgley CM, Manini I, Montomoli E, Smith GL: Prevalence of antibodies to vaccinia virus after smallpox vaccination in Italy. J. Gen. Virol. 86(11), 2955-2960 (2005).

38. Amara RR, Nigam P, Sharma S, Liu J, Bostik V: Long-lived poxvirus immunity, robust CD4 help, and better persistence of CD4 than CD8 T cells. J. Virol. 78(8), 3811-3816 (2004).

39. Combadiere B, Boissonnas A, Carcelain G et al: : Distinct time effects of vaccination on long-term proliferative and IFN- $\gamma$ producing $\mathrm{T}$ cell memory to smallpox in humans. J. Exp. Med. 199(11), 1585-1593 (2004).

40. Frey SE, Newman FK, Cruz J et al:: Doserelated effects of smallpox vaccine. $N$. Engl. J. Med. 346(17), 1275-1280 (2002).

41. Rock MT, Yoder SM, Talbot TR, Edwards KM, Crowe JE Jr: Cellular immune responses to diluted and undiluted aventis pasteur smallpox vaccine. J. Infect. Dis. 194(4), 435-443 (2006).
42. Hsieh SM, Chen SY, Sheu GC et al: Clinical and immunological responses to undiluted and diluted smallpox vaccine with vaccinia virus of Lister strain. Vaccine 24(4), 510-515 (2006).

43. Talbot TR, Stapleton JT, Brady RC et al:: Vaccination success rate and reaction profile with diluted and undiluted smallpox vaccine: a randomized controlled trial. JAMA 292(10), 1205-1212 (2004).

44. Belshe RB, Newman FK, Frey SE et al:: Dose-dependent neutralizing-antibody responses to vaccinia. J. Infect. Dis. 189(3), 493-497 (2004).

45. Frey SE, Couch RB, Tacket CO et al.: Clinical responses to undiluted and diluted smallpox vaccine. N. Engl. J. Med. 346(17), 1265-1274 (2002).

46. McClain DJ, Harrison S, Yeager CL et al:: Immunologic responses to vaccinia vaccines administered by different parenteral routes. J. Infect. Dis. 175(4), 756-763 (1997).

47. Belyakov IM, Earl P, Dzutsev A et al:: Shared modes of protection against poxvirus infection by attenuated and conventional smallpox vaccine viruses. Proc. Natl Acad. Sci. USA 100(16), 9458-9463 (2003).

48. Earl PL, Americo JL, Wyatt LS et al: Immunogenicity of a highly attenuated MVA smallpox vaccine and protection against monkeypox. Nature 428(6979), 182-185 (2004).

49. Vollmar J, Arndtz N, Eckl KM et al:: Safety and immunogenicity of IMVAMUNE, a promising candidate as a third generation smallpox vaccine. Vaccine 24(12), 2065-2070 (2006).

50. Kennedy JS, Frey SE, Yan L et al.: Induction of human T cell-mediated immune responses after primary and secondary smallpox vaccination. J. Infect. Dis. 190(7), 1286-1294 (2004).

51. Rock MT, Yoder SM, Wright PF, Talbot TR, Edwards KM, Crowe JE Jr: Differential regulation of granzyme and perforin in effector and memory $\mathrm{T}$ cells following smallpox immunization. J. Immunol. 174(6), 3757-3764 (2005).

52. Rock MT, Yoder SM, Talbot TR, Edwards KM, Crowe JE Jr: Adverse events after smallpox immunizations are associated with alterations in systemic cytokine levels. J. Infect. Dis. 189(8), 1401-1410 (2004).

53. Weltzin R, Liu J, Pugachev KV et al:: Clonal vaccinia virus grown in cell culture as a new smallpox vaccine. Nat. Med. 9(9), 1125-1130 (2003).

- Description of the generation and initial testing of the first clonal smallpox vaccine. 
54. Artenstein AW, Johnson C, Marbury TC et al:: A novel, cell culture-derived smallpox vaccine in vaccinia-naive adults. Vaccine 23(25), 3301-3309 (2005).

55. Greenberg RN, Kennedy JS, Clanton DJ et al.: Safety and immunogenicity of new cell-cultured smallpox vaccine compared with calf-lymph derived vaccine: a blind, single-centre, randomized controlled trial. Lancet 365(9457), 398-409 (2005).

56. Waibel KH, Golding H, Manischewitz J et al: Clinical and immunological comparison of smallpox vaccine administered to the outer versus the inner upper arms of vaccinia-naive adults. Clin. Infect. Dis. 42(4), e16-e20 (2006).

57. Frey SE, Newman FK, Yan L, Lottenbach KR, Belshe RB: Response to smallpox vaccine in persons immunized in the distant past. JAMA 289(24), 3295-3299 (2003).

58. Ennis FA, Cruz J, Demkowicz WE, Rothman AL, McClain DJ: Primary induction of human $\mathrm{CD} 8^{+}$cytotoxic $\mathrm{T}$ lymphocytes and interferon- $\gamma$-producing $\mathrm{T}$ cells after smallpox vaccination. J. Infect. Dis. 185(11), 1657-1659 (2002).

59. Greenberg RN, Schosser RH, Plummer EA et al: Urticaria, exanthems, and other benign dermatologic reactions to smallpox vaccination in adults. Clin. Infect. Dis. 38(7), 958-965 (2004).

60. Kim SH, Yeo SG, Jang HC et al:: Clinical responses to smallpox vaccine in vaccinianaive and previously vaccinated populations: undiluted and diluted Lancy-Vaxina vaccine in a single-blind, randomized, prospective trial. J. Infect. Dis. 192(6), 1066-1070 (2005).

61. Kim SH, Yeo SG, Cho JH et al:: Cell-mediated immune responses to smallpox vaccination. Clin. Vaccine Immunol. 13(10), 1172-1174 (2006).

62. Smith CL, Mirza F, Pasquetto V et al.: Immunodominance of poxviral-specific CTL in a human trial of recombinantmodified vaccinia Ankara. J. Immunol. 175(12), 8431-8437 (2005).

- Demonstrates that when recombinant VACV vaccines are used in humans, CD8 ${ }^{+}$ $T$ cells recognising vector specificities dominate responses.

63. Harrington LE, van der Most R, Whitton JL, Ahmed R: Recombinant vaccinia virus-induced T-cell immunity: quantitation of the response to the virus vector and the foreign epitope. J. Virol. 76(7), 3329-3337 (2002).
- First study to investigate the extent to which responses to the vector dominate immunity to recombinant $\mathrm{VACV}$ vaccines.

64. Xu R, Johnson AJ, Liggitt D, Bevan MJ: Cellular and humoral immunity against vaccinia virus infection of mice. J. Immunol. 172(10), 6265-6271 (2004).

65. Matsui M, Moriya O, Yoshimoto T, Akatsuka T: T-bet is required for protection against vaccinia virus infection. J. Virol. 79(20), 12798-12806 (2005).

66. Reading PC, Smith GL: A kinetic analysis of immune mediators in the lungs of mice infected with vaccinia virus and comparison with intradermal infection. J. Gen. Virol. 84(Pt 8), 1973-1983 (2003).

67. Tscharke DC, Reading PC, Smith GL: Dermal infection with vaccinia virus reveals roles for virus proteins not seen using other inoculation routes. J. Gen. Virol. 83(Pt 8), 1977-1986 (2002)

- VACV immunomodulators and, therefore, presumably, host immune mediators have different roles in different models of VACV infection in mice.

68. Belyakov IM, Isakov D, Zhu Q, Dzutsev A, Klinman D, Berzofsky JA: Enhancement of $\mathrm{CD}^{+} \mathrm{T}$ cell immunity in the lung by $\mathrm{CpG}$ oligodeoxynucleotides increases protective efficacy of a modified vaccinia Ankara vaccine against lethal poxvirus infection even in a CD4-deficient host. J. Immunol. 177(9), 6336-6343 (2006).

69. Hooper JW, Custer DM, Schmaljohn CS, Schmaljohn AL: DNA vaccination with vaccinia virus $L 1 R$ and $A 33 R$ genes protects mice against a lethal poxvirus challenge. Virol. 266(2), 329-339 (2000).

70. Wyatt LS, Earl PL, Eller LA, Moss B: Highly attenuated smallpox vaccine protects mice with and without immune deficiencies against pathogenic vaccinia virus challenge. Proc. Natl Acad. Sci. USA 101(13), 4590-4595 (2004).

71. Howell MD, Gallo RL, Boguniewicz M et al:: Cytokine milieu of atopic dermatitis skin subverts the innate immune response to vaccinia virus. Immunity $24(3), 341-348$ (2006).

72. Howell MD, Jones JF, Kisich KO, Streib JE, Gallo RL, Leung DYM: Selective killing of vaccinia virus by LL-37: implications for eczema vaccinatum. J. Immunol. 172(3), 1763-1767 (2004).

- Combines mouse and human culture models to implicate deficiency in an antimicrobial peptide in the cause of eczema vaccinatum.
73. Zhou J, Crawford L, McLean L et al: Increased antibody responses to human papillomavirus type $16 \mathrm{~L} 1$ protein expressed by recombinant vaccinia virus lacking serine protease inhibitor genes. J. Gen. Virol. 71 (Pt 9), 2185-2190 (1990).

74. Staib C, Kisling S, Erfle V, Sutter G: Inactivation of the viral interleukin $1 \beta$ receptor improves $\mathrm{CD} 8^{+} \mathrm{T}$-cell memory responses elicited upon immunization with modified vaccinia virus Ankara. J. Gen. Virol. 86(7), 1997-2006 (2005).

75. Clark RH, Kenyon JC, Bartlett NW, Tscharke DC, Smith GL: Deletion of gene $A 41 L$ enhances vaccinia virus immunogenicity and vaccine efficacy. J. Gen. Virol. 87(1), 29-38 (2006).

76. Jackson SS, Ilyinskii P, Philippon V et al:: Role of genes that modulate host immune responses in the immunogenicity and pathogenicity of vaccinia virus. J. Virol. 79(10), 6554-6559 (2005).

77. Gardner JD, Tscharke DC, Reading PC, Smith GL: Vaccinia virus semaphorin A39R is a $50-55 \mathrm{kDa}$ secreted glycoprotein that affects the outcome of infection in a murine intradermal model. J. Gen. Virol. 82(9), 2083-2093 (2001).

78. Liu L, Fuhlbrigge RC, Karibian K, Tian T, Kupper TS: Dynamic programming of $\mathrm{CD}^{+} \mathrm{T}$ cell trafficking after live viral immunization. Immunity 25(3), 511-520 (2006).

\section{Websites}

101. Smallpox and Its Eradication whqlibdoc.who.int/smallpox/ 9241561106.pdf

102. Immune Epitope Database and Analysis Resource www.immuneepitope.org

\section{Affiliation}

- David C Tscharke The Australian National University, School of Biochemistry \& Molecular Biology, Canberra, ACT, 0200, Australia

Tel.: +61261253020;

Fax: +6126125 0313;

david.tscharke@anu.edu.au 